\title{
Androgen receptor: a potential therapeutic target for glioblastoma
}

\author{
Nomi Zalcman ${ }^{1,2, *}$, Tamar Canello, ${ }^{1,2}{ }^{*}$, Haim Ovadia², Hanna Charbit ${ }^{1,2}$, Bracha

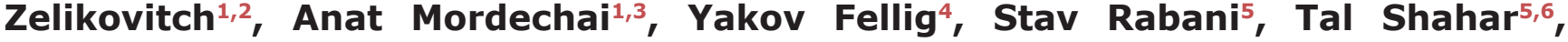 \\ Alexander Lossos ${ }^{1,2,3, * *}$ and Iris Lavon ${ }^{1,2, * *}$ \\ ${ }^{1}$ Leslie and Michael Gaffin Center for Neuro-Oncology, Hadassah-Hebrew University Medical Center, Jerusalem, Israel \\ ${ }^{2}$ Department of Neurology, Agnes Ginges Center for Human Neurogenetics, Hadassah-Hebrew University Medical Center, \\ Jerusalem, Israel \\ ${ }^{3}$ Department of Oncology, Hadassah-Hebrew University Medical Center, Jerusalem, Israel \\ ${ }^{4}$ Department of Pathology, Hadassah-Hebrew University Medical Center, Jerusalem, Israel \\ ${ }^{5}$ The Laboratory for Molecular Neuro-Oncology, Department of Neurosurgery, Tel Aviv Medical Center, Tel Aviv, Israel \\ ${ }^{6}$ Department of Neurosurgery, Shaare Zedek Medical Center, Jerusalem, Israel \\ *The first two authors contributed equally to the study \\ ** The last two authors contributed equally to the study \\ Correspondence to: Iris Lavon, email: IrisL@Hadassah.org.il \\ Keywords: androgen receptor (AR); gliomas; AR variant 7 (AR3); AR antagonist; glioblastoma (GBM) \\ Received: November 15, $2017 \quad$ Accepted: March 14, $2018 \quad$ Published: April 13, 2018 \\ Copyright: Zalcman et al. This is an open-access article distributed under the terms of the Creative Commons Attribution License \\ 3.0 (CC BY 3.0), which permits unrestricted use, distribution, and reproduction in any medium, provided the original author and \\ source are credited.
}

\section{ABSTRACT}

The median survival time of patients with glioblastoma is still poor (14.6 month), partly due to a lack of effective treatment.

We have observed that androgen receptor (AR) is amplified in glioblastomas at the DNA, RNA and protein levels. The AR gene was amplified in $27 \%$ of glioblastoma specimens from men $(n=22)$ and of $38.2 \%$ from women $(n=21)$. AR-RNA was overexpressed ( $>2.5$ fold) in $93 \%(n=30)$, and AR-protein was induced ( $>$ two fold) in $56 \%$ of the glioblastomas samples $(n=16)$. Thirty percent of the glioblastomas $(n=21)$ also expressed a constitutively active AR-splice-variant (AR-V7/AR3) lacking the Ligand-Binding-Domain. Following these findings, we examined the effect of pharmacological inhibition of androgen receptor in vitro and in vivo, as well as of genetic silencing of the receptor in glioblastoma cell lines. AR antagonists, induced concentration-dependent death in three glioblastoma cell lines, as well as in two glioma initiating cell lines. Silencing of AR expression by siRNA induced cell death in the three tested glioblastoma cell lines. Enzalutamide given orally to nude mice bearing subcutaneous human glioma xenografts resulted in a $72 \%$ reduction in tumor volume $(p=0.0027)$.

The presence of AR-V7/AR3 in glioblastoma, together with the present data showing that genetic silencing of the full length AR in cell lines and pharmacological inhibition of $A R$, induce GBM cell death in vivo and in vitro, point to the important role of $A R$ in GBM survival and render a potential therapeutic target for this devastating disease. 


\section{INTRODUCTION}

Glioblastoma (GBM) is the most common and the most aggressive primary brain tumor, with a very poor prognosis. The most common genetic aberrations associated with malignant glioma are amplification or activating mutations of the epidermal growth factor receptor (EGFR) or both [1-3]. Activation of EGFR results in a downstream phosphoinositol 3 kinase (PI3 kinase)/ Akt cascade, facilitating cell survival, proliferation, and migration, and thus is crucial to tumorigenesis.

The association between sex steroid receptors and brain tumors was first described in 1983 [4], but in contrast to the well-established oncogenic role played by androgen receptor (AR) in prostate cancer (reviewed in [5]) and the growing evidence of its role in breast cancer (reviewed in [6]), the expression and significance of AR in GBM is controversial and poorly studied.

The AR gene is mapped to $\mathrm{Xq} 12$. It functions as a steroid-hormone-activated-transcription-factor and is composed of the N-Terminal-Regulatory-Domain, the DNA-Binding-Domain and the Ligand-BindingDomain (LBD). In the presence of ligand, the ligandbinding domain is released from heat shock protein and $\mathrm{AR}$ is translocated into the nucleus, where it binds to the androgen-response-element in the promoter and stimulates transcription of androgen- responsive genes [7]. It has been shown in prostate and breast cancers that activation of AR can be achieved also by ligand-independent signaling through crosstalk with other molecular signaling pathways, as a consequence of activation of the downstream PI3K/ AKT/mTOR. Such pathways include receptor tyrosine kinases (RTKs), such as the insulin-like growth factor keratinocyte growth factor (KGF), EGFR and Human Epidermal Growth Factor Receptor 2 (HER2) [8-11]. These AR-independent pathways can promote cancer cell survival and growth (reviewed in [7]) and appear to be a major androgen-independent driver of AR-regulated gene expression in castration-resistant prostate cancer.

AR splice variants lacking the LBD, such as ARV7/AR3, which arise primarily through exon skipping and cryptic exon inclusion, are activated by a ligandindependent mechanism such as the ones mentioned above. [8]. Although AR-regulated signaling pathways are well established in prostate cancer, the involvement of AR in GBM and the potential AR-dependent or independent regulated signaling pathway in GBM is not known.

AR signaling inhibitors such as enzalutamide target the AR signaling pathway at three key stages: by blocking binding of androgens to AR, by inhibiting nuclear translocation of activated AR, and by impairing binding of activated AR to DNA [9].

The findings from our laboratory, some of which were previously presented [10], show amplification and overexpression of AR in GBM. This led to the present investigation of the effect of pharmacological inhibition of AR in vitro and in the subcutaneous in vivo model, as well as the effect of genetic silencing of the receptor in GBM cell lines.

\section{RESULTS}

\section{Variation in AR DNA copy number and in RNA and protein expression levels in GBM}

Focal CNV analysis of the AR chromosomal region with Droplet Digital ${ }^{\mathrm{TM}}$ PCR (ddPCR ${ }^{\mathrm{TM}}$ ) showed AR amplification in $27 \%$ of GBM specimens from men $(n=22)$ and $38.2 \%$ of women $(n=21)$ (Table 1). Amplification of the AR gene was observed (two copies) also in the T98G cell line, derived from the GBM of a male patient, but not in U87MG or A172. The analysis was performed following the observation, made according to an OncoScan FFPE array, of LOH at the chromosomal locus containing the AR gene, accompanied by amplification of the other allele in 4/5 GBM specimens from women [10] (Supplementary Figure 1). To determine whether this AR gene variation influences AR expression, AR-RNA and protein expression were studied.

Quantitative-PCR (qPCR) showed that ARRNA was overexpressed (2.76-315,984 fold) in 93\% of 30 glioblastoma samples of both men and women patients (Figure 1A; Table 2 ). Further analysis of AR RNA amplification from several datasets, including the TCGA dataset, with Oncomine ${ }^{\mathrm{TM}}$ software (Compendia Bioscience, Ann Arbor, MI, USA), validated the RNA results (Figure 1B-1C) and showed that AR-RNA is overexpressed also in low-grade gliomas (Figure 1D). Analysis of prostate cancer datasets revealed that the AR RNA fold change in prostate cancer is similar to the present findings in GBM (Supplementary Figure 2A, 2B).

Detailed correlation analysis between AR expression and clinical parameters was adapted from the analysis performed on 24,519 genes by the Broad Institute TCGA Genome Data Analysis Center in 519 GBM tumors [11]. The analysis showed a significant positive correlation between AR expression and age $(\mathrm{R}=0.1105 ; \mathrm{P}=0.01132 ; \mathrm{Q}=0.0765)$ and a significant negative correlation with the Karnofsky performance score $(\mathrm{R}=-0.0978 ; \mathrm{P}=0.05173 ; \mathrm{Q}=0.324)$. No correlation was found between AR expression and survival, gender, radiotherapy, race or ethnicity (Table 3).

Western blot analysis revealed AR protein induction (2-106-fold) in $56 \%$ of the glioblastomas samples $(n=16)$ of both men and women patients (Figure 2A; Table 2), and in the three GBM cell lines tested (2B).

\section{AR-V7/AR3, which lacks the ligand-binding domain, occurs in GBM}

The AR-V7/AR3, known to be upregulated only in tumors and activated via a ligand-independent mechanism, was found in $30 \%$ of the GBM surgical specimens, in addition to the wild type AR ( $\mathrm{n}=21$ ) (Figure 2C). 
Table 1: AR copy number variation (CNV) in GBM

\begin{tabular}{|c|c|c|c|c|c|}
\hline \multicolumn{3}{|c|}{$\operatorname{Men}(n=22)$} & \multicolumn{3}{|c|}{ Women $(n=21)$} \\
\hline AR Copy number & No. & $\%$ & AR Copy number & No. & $\%$ \\
\hline 1 & 16 & $72.7 \%$ & 1 & 6 & $28.5 \%$ \\
\hline 2 & 5 & $22.8 \%$ & 2 & 7 & $33.3 \%$ \\
\hline 3 & 1 & $4.5 \%$ & 3 & 8 & $38.2 \%$ \\
\hline
\end{tabular}

DNA was extracted from tumors of 22 men and 21 women and CNV was studied with ddPCR.

\section{Antagonism of AR in glioma cell lines induces dose-dependent cell death}

The finding of AR overexpression in GBM in the present study and based on the documented benefit of AR inhibitors in prostate cancer, the effect of AR inhibitors bicalutamide and enzalutamide on the survival of glioma cell lines A172, U87MG and T98G was explored. Prostate carcinoma cell line PC3, which does not express AR [12], served as negative control. Both inhibitors induced significant $(\mathrm{p}<0.05$ and $\mathrm{p}<0.01$, as indicated $)$ dosedependent cell death in all glioma cell lines, enzalutamide showing the higher efficacy (Figure 3A-3C). No effect was seen in the PC3 line (Supplementary Figure 3A).

\section{A}

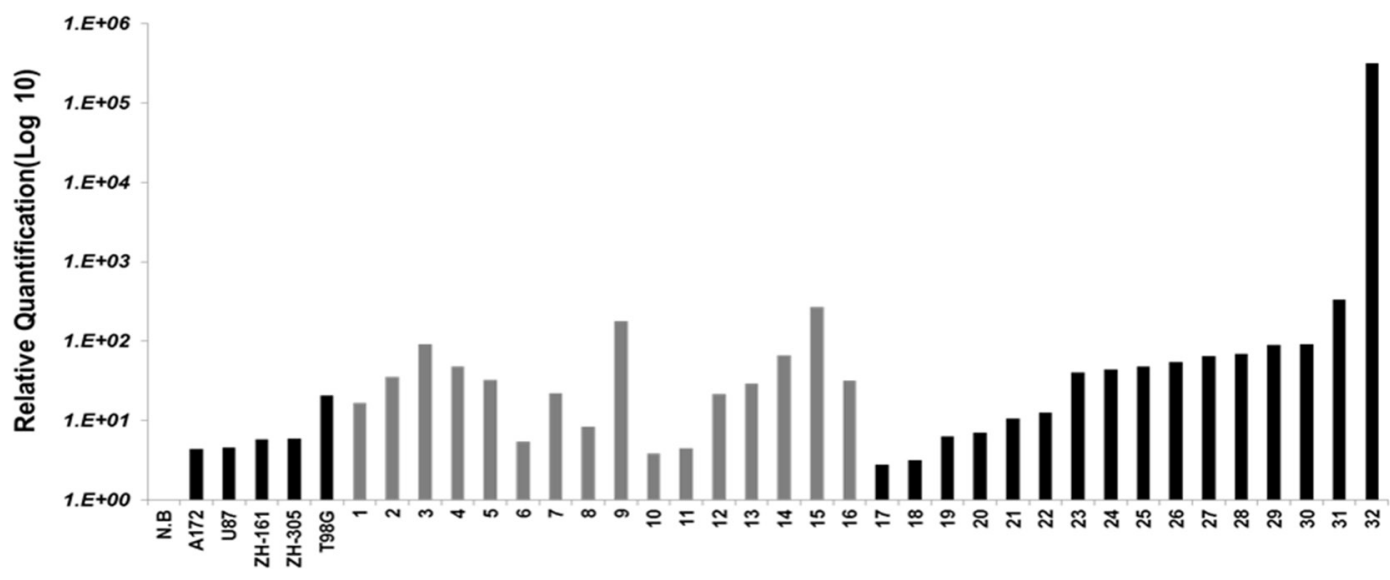

B

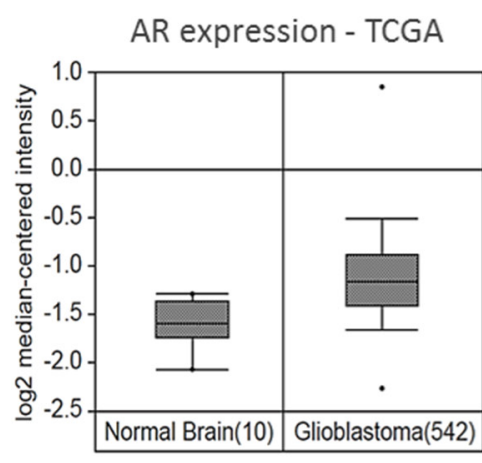

GBM vs. Normal

Fold change 1.744; $P=1.05 E-6$
C

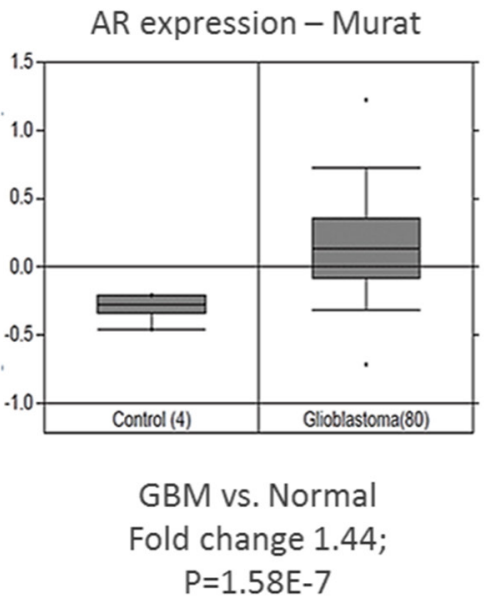

D

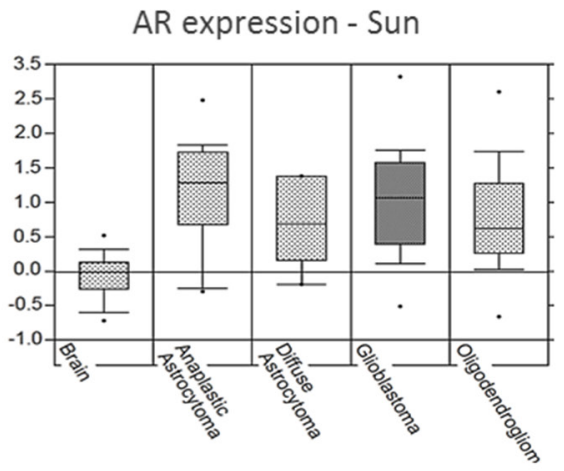

GBM vs. Normal

Fold change $2.12 ; \mathrm{P}=7.1 \mathrm{E}-17$

Figure 1: AR RNA expression in GBM tissue samples. (A) Quantitative real-time RT PCR of RNA extracted from GBM samples of both male and female patients shows significant (2.76- to 315-fold) induction of AR-RNA in $93 \%$ of the samples. Relative AR mRNA quantification was compared with that of a commercial RNA mixture of 23 normal brains (NB); following normalization to HPRT and TBP1 (The Y-axis is on a $\log _{10}$ scale) in 30 GBM tumor samples and three GBM cell lines and two GIC cell lines (X-axis). (B-D) AR RNA expression in tumors compared with that in normal tissue analyzed from several datasets with Oncomine ${ }^{\text {TM }}$ (B) GBM AR RNA expression of the TCGA database; (C) GBM AR RNA expression of the Murat cohort; (D) glioma AR RNA expression of the Sun cohort. 
Table 2: Characteristics of 32 patients with glioblastoma

\begin{tabular}{|c|c|c|c|c|c|}
\hline $\begin{array}{l}\text { ID } \\
\text { (Figure 1A, 1E) }\end{array}$ & Sex & Age & Survival (month) & MGMT Methylation & $\begin{array}{c}\text { Admission ECOG } \\
\text { score }\end{array}$ \\
\hline 1 & M & 54 & 5.6 & UM & 1 \\
\hline 2 & $\mathrm{~F}$ & 48 & 8.1 & UM & 1 \\
\hline 3 & M & 61 & 4 & $\mathrm{ME}$ & 1 \\
\hline 4 & M & 30 & 83 & $\mathrm{ME}$ & 0 \\
\hline 5 & $\mathrm{~F}$ & 58 & 31.2 & UM & 1 \\
\hline 6 & $\mathrm{~F}$ & 66 & 27.6 & ME & 0 \\
\hline 7 & $\mathrm{~F}$ & 37 & 52.7 & $\mathrm{ME}$ & 0 \\
\hline 8 & $\mathrm{~F}$ & 67 & 27.1 & UM & 0 \\
\hline 9 & M & 63 & 7.6 & ME & 0 \\
\hline 10 & $\mathrm{~F}$ & 72 & 6.5 & UM & 1 \\
\hline 11 & $\mathrm{~F}$ & 68 & 71.3 & $\mathrm{ME}$ & 0 \\
\hline 12 & $\mathrm{~F}$ & 30 & 34.1 & UM & 1 \\
\hline 13 & $\mathrm{~F}$ & 55 & 21.9 & UM & 0 \\
\hline 14 & M & 34 & 66.5 & UM & 0 \\
\hline 15 & M & 50 & 4.2 & UM & 1 \\
\hline 16 & M & 71 & 4.3 & UM & 0 \\
\hline 17 & $\mathrm{M}$ & 60 & 3.5 & UM & 1 \\
\hline 18 & F & 59 & 29.6 & UM & 1 \\
\hline 19 & $\mathrm{M}$ & 62 & 28.2 & UM & 1 \\
\hline 20 & F & 74 & 5.5 & UM & 1 \\
\hline 21 & F & 68 & 17.7 & UM & 0 \\
\hline 22 & $\mathrm{~F}$ & 70 & 4 & $\mathrm{ME}$ & 1 \\
\hline 23 & M & 55 & 7.8 & $\mathrm{ME}$ & 2 \\
\hline 24 & $\mathrm{M}$ & 57 & 83 & $\mathrm{ME}$ & 0 \\
\hline 25 & $\mathrm{M}$ & 63 & 111.4 & UM & 1 \\
\hline 26 & $\mathrm{M}$ & 59 & 30.8 & UM & 1 \\
\hline 27 & $\mathrm{M}$ & 62 & 9.3 & UM & 1 \\
\hline 28 & F & 68 & 63.1 & $\mathrm{ME}$ & 0 \\
\hline 29 & $\mathrm{~F}$ & 54 & 33.3 & $\mathrm{ME}$ & 0 \\
\hline 30 & $\mathrm{M}$ & 62 & 4.1 & $\mathrm{ME}$ & 1 \\
\hline 31 & $\mathrm{~F}$ & 63 & 73.9 & $\mathrm{ME}$ & 0 \\
\hline 32 & M & 68 & 8.9 & UM & 1 \\
\hline
\end{tabular}

Abbreviations: F, female; M, Male; ME, methylated; UM, unmethylated; MGMT, O6-methylguanine methyltransferase ECOG, the Eastern Cooperative Oncology Group Performance Scale.

IDH1 status: Patients (8) and (22) carry the IDH1 R132H mutation, in the rest of the patients IDH is intact. 
Table 3: Correlation between AR expression and clinical features

\begin{tabular}{|c|c|}
\hline Clinical features & Statistical test and results \\
\hline Days to death or last follow up & $\begin{array}{c}\text { Logrank } \\
\mathrm{P}=0.787 \\
\mathrm{Q}=0.920\end{array}$ \\
\hline Years to birth & $\begin{array}{l}\text { Spearman Correlation } \\
\qquad \begin{array}{c}\mathrm{R}=0.1105 \\
\mathrm{P}=\mathbf{0 . 0 1 1 3 2} \\
\mathrm{Q}=\mathbf{0 . 0 7 6 5}\end{array}\end{array}$ \\
\hline Gender & $\begin{array}{l}\text { Wilcoxon test } \\
\begin{array}{c}\mathrm{P}=0.8432 \\
\mathrm{Q}=0.971\end{array}\end{array}$ \\
\hline Radiation therapy & $\begin{array}{c}\text { Wilcoxon test } \\
\mathrm{P}=0.895 \\
\mathrm{Q}=0.98\end{array}$ \\
\hline Karnofsky performance score & $\begin{array}{l}\text { Spearman Correlation } \\
\qquad \begin{array}{c}\mathrm{R}=-0.0978 \\
\mathrm{P}=\mathbf{0 . 0 5 1 7 3} \\
\mathrm{Q}=0.324\end{array}\end{array}$ \\
\hline Race & 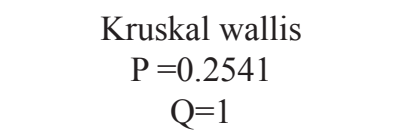 \\
\hline Ethnicity & $\begin{array}{l}\text { Wilcoxon test } \\
\qquad \begin{array}{l}\mathrm{P}=0.351 \\
\mathrm{Q}=0.952\end{array}\end{array}$ \\
\hline
\end{tabular}

Significance (bold) when P value $<0.05$ and Q value (False Discovery Rate) $<0.3$.

A table drawn from the analysis made by the Broad Institute TCGA Genome Data Analysis Center [11] showing the results of the association between the clinical features and AR expression across 519 tumor samples according to the statistical methods used.

To standardize the experiments and avoid the influence of Fetal Bovine Serum (FBS)-derived steroid hormone, the cell medium was supplemented with charcoal/dextrantreated (stripped) FBS and a physiological dose of DHT $(10 \mathrm{nM})$. The DHT dose had no effect on the proliferation of the GBM cell lines (Figure 3). Treatment of the cells with enzalutamide in cell medium supplemented with full serum, without the addition of DHT, yielded similar results (Supplementary Figure 3B, 3C).

In view of the results obtained with the standard cell lines A172, U87MG and T98G, the efficacy of enzalutamide was tested also on two glioma-initiating cell (GIC) lines, ZH-161 and ZH-305 [13, 14]. Both GIC lines, like the T98G cell line, expressed high levels of full length AR (Figure 1A) and even higher levels of AR-V7/AR3 (1.79 and 3.5-fold respectively compared with T98G). Treatment of the lines with enzalutamide showed low but significant efficacy (Figure 3D, 3E).

\section{Silencing of AR with siRNA in glioma cell lines induces cell death}

To test whether AR has a specific effect on GBM cell viability, the three GBM cell lines were transfected with siRNA targeted to the full length AR or with nontargeted siRNA. Real time RT-PCR, confirmed a reduction in AR transcription in cells transfected with siRNA targeted to the full length AR compared with that in cells transfected with control siRNA. In all the three cell lines there was a correlation between tumor cell death and the extent of reduction of AR expression (Figure 3F, 3G).

\section{AR antagonist induces apoptotic cell death}

Cell cycle analysis of the three glioma cell lines treated with enzalutamide revealed a dose-dependent number of cells in the sub-G1 phase, suggesting that apoptosis was one of the mechanisms responsible for cell death (Figure 4A). The finding was further validated by immunohistochemical staining of the enzalutamide-treated cells with anti-cleaved caspase 3 (Figure 4B).

\section{AR antagonist enzalutamide significantly reduces the growth of human glioblastoma in a xenograft mouse model}

The efficacy of enzalutamide was studied in vivo in subcutaneous xenografts of U87MG human glioblastoma. 
On day 7 when the tumors reached an average volume of about $50 \mathrm{~mm}^{3}$, the mice were randomly assigned to two treatment groups, based on caliper measurements. All the mice were treated three times weekly by oral gavage of $20 \mathrm{mg} / \mathrm{kg}$ XTANDI $^{\circledR}$ (enzalutamide) or vehicle. The study was terminated on day 31 post tumor inoculation when the tumor volume of half of the mice in the vehicle group reached $800-1000 \mathrm{~mm}^{3}$. At the endpoint of the experiment, there was a $72 \%$ reduction in tumor volume in the group treated with XTANDI vs that in mice treated with vehicle $(p=0.0027)$ (Figure 5)

\section{DISCUSSION}

The results of this study show for the first time AR amplification at the DNA, RNA and protein levels in GBM samples from both men and women. The AR-RNA expression findings were validated in 703 glioblastomas by analysis of several datasets, including the TCGA. Bao et al.[15] confirmed some of our previous results [10] regarding AR protein expression. No correlation was found between the expression of AR RNA and AR protein. This discrepancy may be related to differential post-transcriptional regulatory mechanisms involving the AR gene.

The significant negative correlation of AR expression with the Karnofsky performance score obtained from the detailed correlation between AR expression and clinical parameters according to the TCGA dataset, may suggest that there is a correlation between AR expression and tumor aggressiveness. The finding that there was no correlation between AR expression and survival could be attributed to the non-standardized background of the clinical dataset. The absent correlation between AR expression and gender supports our findings that $A R$ overexpression occurs in tumors from both men and women.

AR copy number variation is probably not the sole mechanism responsible for AR RNA and protein overexpression. This may be concluded from the finding that AR DNA amplification was found only in the T98G cell line (1/3 lines), whereas AR RNA and protein overexpression was found in all cell lines (with higher overexpression in the T98G cell line). Furthermore,

A

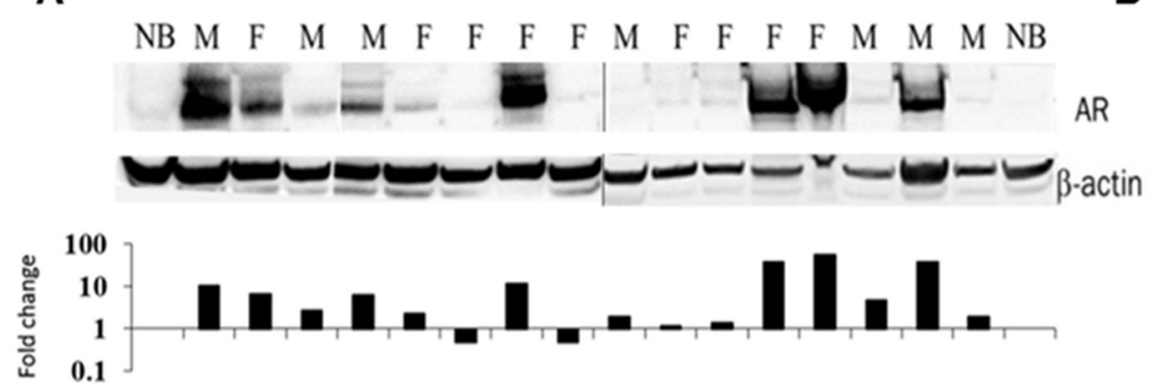

B

$\begin{array}{lllllllllllllllllllllll}\mathrm{NB} & 1 & 2 & 3 & 4 & 5 & 6 & 7 & 8 & 9 & 10 & 11 & 12 & 13 & 14 & 15 & 16 & \mathrm{NB}\end{array}$

C

$\begin{array}{lllllllllllllllllllllllll}\text { A172 U87 T980 M N8 } & 1 & 2 & 3 & M & 4 & 5 & 6 & 7 & 8 & 9 & 10 & 11 & 12 & 13 & 14 & 15 & 16 & 17 & 18 & 19 & 20 & 21 & M\end{array}$

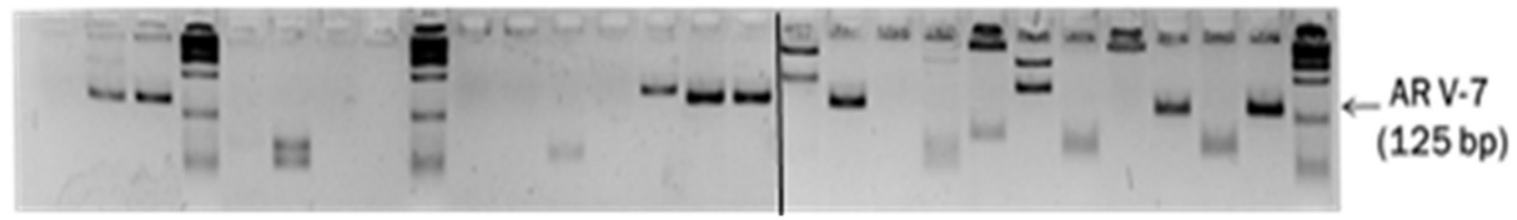

Figure 2: AR protein expression and the presence of the ligand-independent AR splice variant 7 (AR3) in GBM samples. (A) Western blot analysis by sequential probing with polyclonal antibody against AR (N20) or anti- $\beta$-Actin (AC-74) of 16 GBM samples (these samples were also analyzed for AR-RNA expression and are marked in grey in Figure 1A) of Females (F) and male (M) and one normal brain. The figure is composed of two gels that were run simultaneously. Protein fold change (the Y-axis is on a log ${ }_{10}$ scale) of each tumor sample compared with that of normal brain was calculated according to band densitometry analysis with alphaview software, following normalization to $\beta$-Actin (lower panel). (B) Western blot analysis, with sequential probing with polyclonal antibody against AR (N20) or monoclonal anti- GAPDH (0411) of HEK 293, A172, U87MG and T98G cell lines. (C) AR-V7/AR3 was analyzed by quantitative PCR of 21 GBM specimens, a commercial mixture of total RNA from 23 normal brains (NB) and 3 glioma cell lines, as indicated. The resulting 125-bp fragments, together with a 100-bp DNA ladder $(\mathrm{M})$ were electrophoresed on 3.5\% metaphor and visualized with ethidium bromide. The figure is composed of two gels that were run together. 
only about $1 / 3$ of the specimens showed AR DNA amplification, whereas $93 \%$ of the patients demonstrated AR RNA overexpression and 56\% showed AR protein overexpression. A possible other mechanism may include activation of the enhancer in the AR second intron contributing to increased AR expression at low androgen levels, as in castration-resistant prostate cancer [16].

In the present investigation, pharmacological inhibition of AR with AR antagonists in three glioma cell lines, as well as in two GICs, induced dose concentrationdependent death. Cell cycle analysis of the AR antagonisttreated cells, as well as staining with anti- cleaved caspase 3, suggest that the mechanism responsible for cell death is at least in part, apoptosis. Genetic silencing of AR expression by siRNA resulted in reduced GBM cell viability. These finding validate the results of the pharmacological AR inhibition and indicate that AR has a specific role in GBM cell survival.

In addition, we now demonstrate that $30 \%$ of GBM samples expressed constitutively-activated AR-V7/ AR3 lacking the LBD. This variant is a major androgenindependent driver of AR-regulated gene expression in advanced prostate cancer [8]. The existence of such a variant in GBM, together with the finding that silencing of the full length AR induces GBM cell death, might point to the important role played by AR in GBM growth.

The AR-V7/AR3 variant was not detected by Bao et al. [15] in U87MG or U251 glioma cell lines, probably because of differences in the sensitivity of the methods used. In the present study, the standard industrial qPCR thermocycling protocol of 40 amplification cycles was used and AR-V7/AR3 was detected in U87MG at cycle
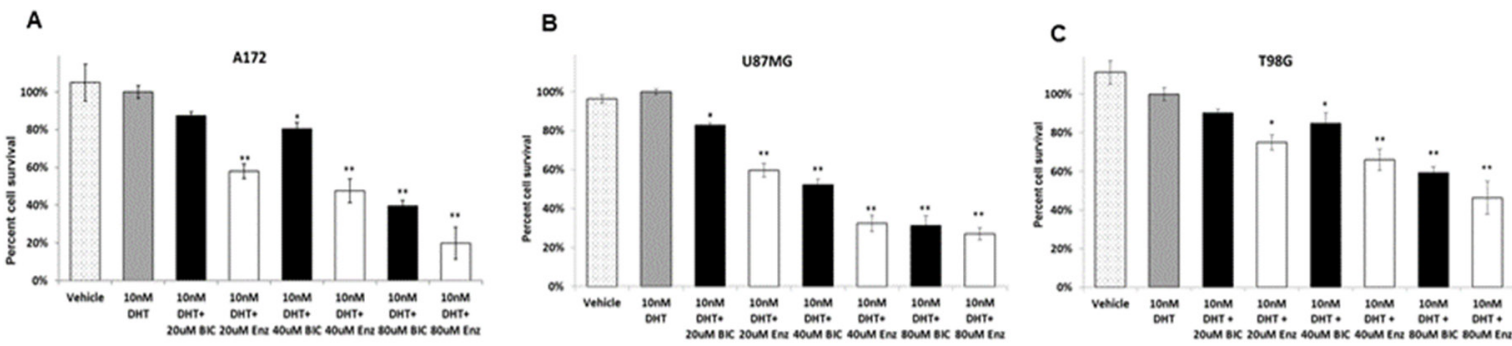

D

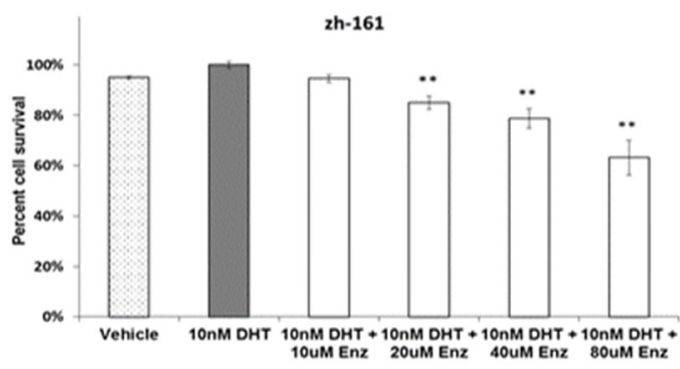

$\mathbf{F}$

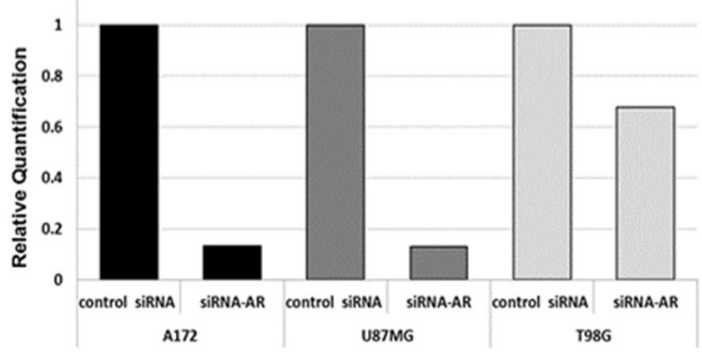

E

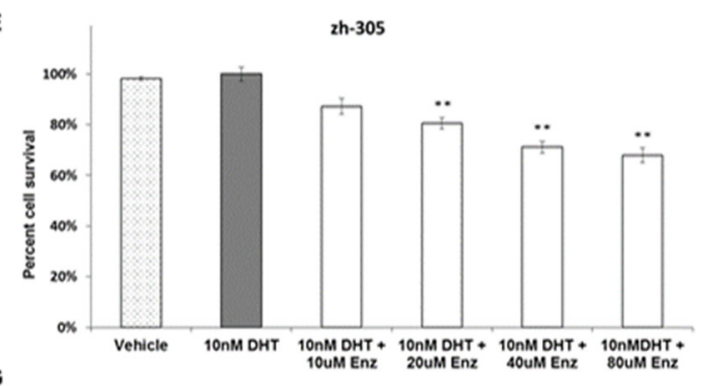

G

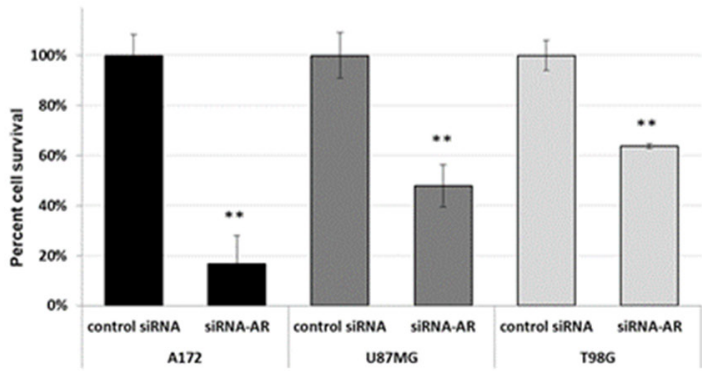

Figure 3: Pharmacological inhibition and silencing of $\mathbf{A R}$ in glioma cell lines. (A-C) GBM cell lines were maintained in culture medium supplemented with androgens (as well as other steroids)-stripped FBS. (D, E) GIC cell lines were treated with neurobasal medium without FBS. (A-E) both GBM cell lines and GIC cell lines were treated with vehicle ( $0.15 \%$ ethanol) (white bars with black dots) or with a physiological dose $(10 \mathrm{~nm})$ of DHT alone (gray bars) or in combination with the indicated doses of bicalutamide (BIC, black bars) or enzalutamide (ENZ, white bars) (X-axis) for $72 \mathrm{hrs.} \mathrm{Cell} \mathrm{viability} \mathrm{was} \mathrm{determined} \mathrm{as} \mathrm{described} \mathrm{in} \mathrm{Methods} \mathrm{and} \mathrm{is} \mathrm{expressed} \mathrm{as} \mathrm{the}$ percentage of viable cells following treatment with DHT (Y-axis). (A) A172 cell line; (B) U87MG cell line; (C) T98G cell line; (D) ZH161 cell line; (E) ZH-305 cell line. (F-G) Cells were transfected with $1.2 \mathrm{nM}$ of non-targeted siRNA (control siRNA) or siRNAs targeting human AR. (F) RNA interference determined by Quantitative real-time RT PCR 24 hrs later. (G) Cell viability determined with the crystal violet assay $72 \mathrm{~h}$ later. All experiments were repeated at least three times. The results of the viability experiments are presented as the mean $\pm \mathrm{SD}{ }^{*} \mathrm{P}<0.05,{ }^{* *} \mathrm{P}<0.01$ versus control group. 


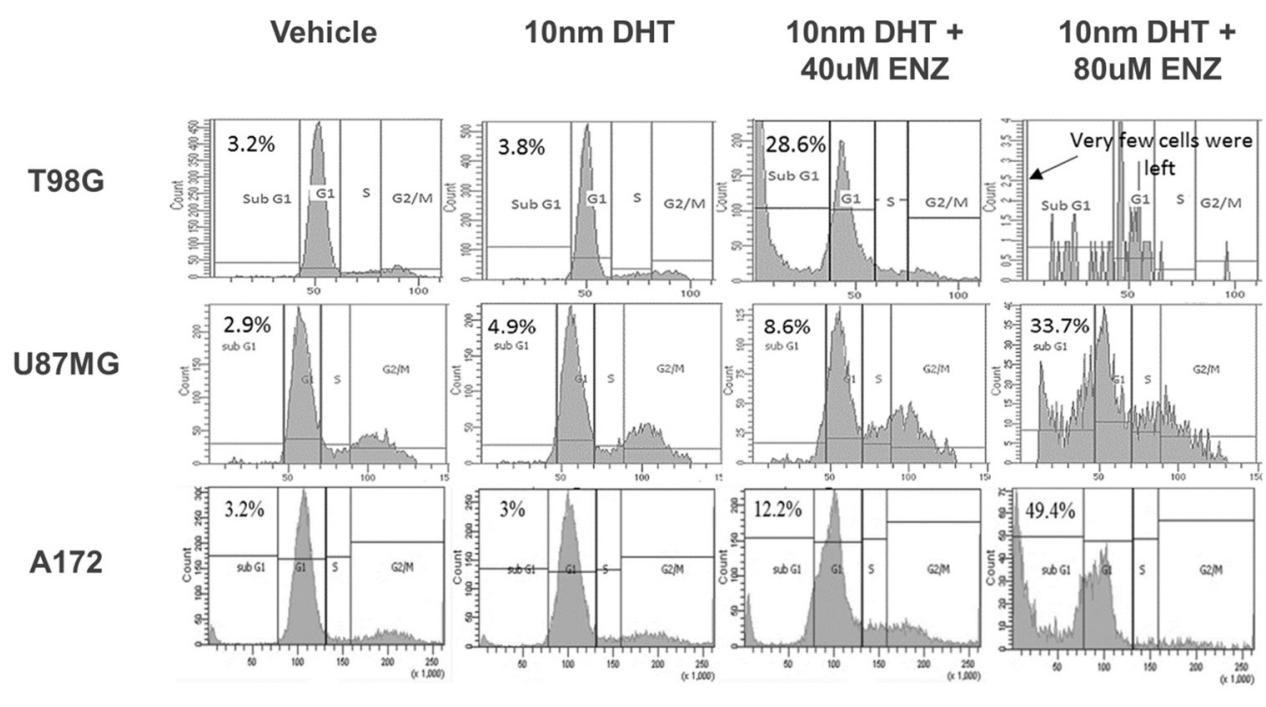

B

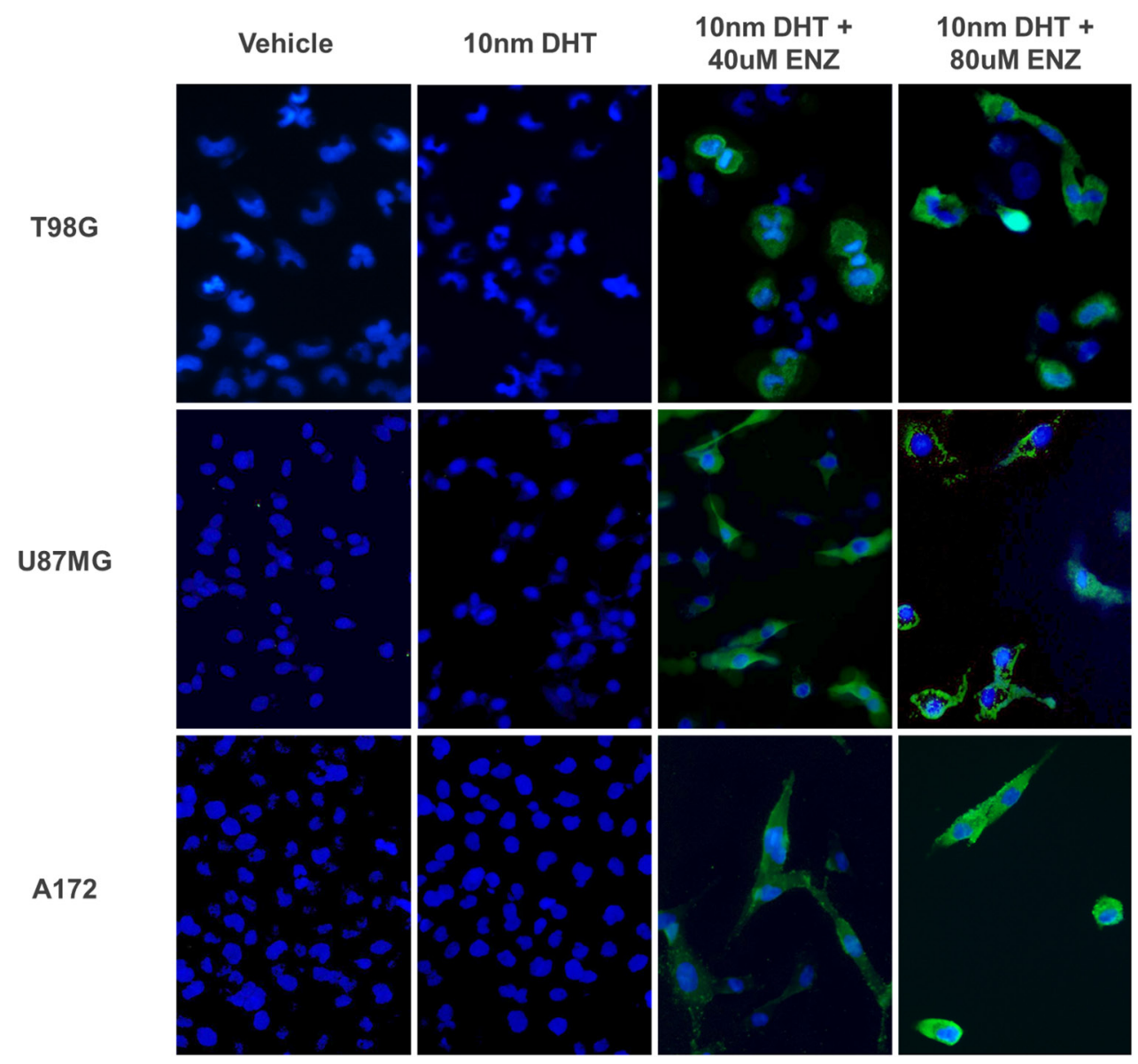

Figure 4: Analysis of PI labeling and cleaved caspase 3 in the A172 U87MG and T98G cell lines after enzalutamide treatment. Glioma cell lines were treated with vehicle $(0.15 \%$ ethanol), $10 \mathrm{~nm}$ DHT with or without 40 or $80 \mu \mathrm{M}$ enzalutamide, as indicated and subjected to PI labeling (A) or to cleaved caspase 3 immunofluorescence (B). (A) DNA content histogram following cell cycle analysis with propidium iodide (PI). PI fluorescence intensity was captured with flow cytometry via the FL2 channel and 488nM laser excitation. The percentage of cells at sub-G1 is indicated for each treatment. Enzalutamide sensitive cell lines A172 and U87 were analyzed after $48 \mathrm{hrs}$, T98G - after $72 \mathrm{hrs}$. (B) $72 \mathrm{hrs}$ after treatment with enzalutamide the cells were fixed and incubated with primary antibody for Cleaved Caspase-3 (Asp175) and Alexa Fluor 488 conjugate secondary antibody (green). Before visualization the cell nuclei were stained with DAPI (blue). The cells were captured with a VVOS $^{\circledR}$ Digital Microscope at x 200 magnification. 
34, whereas Bao et al., used a semi-quantitative PCR analysis and failed to detect AR-V7/AR3 at cycle 27. The group did not check the presence of AR-V7/AR3 in glioma specimens.

T98G, as well as the GIC cell lines, show high expression of the full length AR and of the constitutive active AR variant. These cell lines showed reduced but still significant susceptibility to AR inhibitors. This residual sensitivity to AR inhibitors could be related to the fact that the mechanism of action of inhibitors such as enzalutamide [9] include, apart from blocking the binding of androgens to AR, inhibition of the nuclear translocation of the activated AR, and impaired binding of activated AR to DNA. Thus, such inhibitors might be active also against ligand-independent AR activation. Moreover, whether AR variants drive therapeutic resistance remains unresolved. Some studies have demonstrated that knockdown of AR-V in cell lines that endogenously express high levels of the variant, restores their sensitivity to anti-androgens $[17,18]$. In contrast, other studies in prostate carcinoma indicate that overexpression of AR-V7 did not impart resistance to enzalutamide [19]. Additionally prostate cancer cell line derived from the Hi-Myc mouse, which expressed AR-V, is sensitive to enzalutamide [20].

It has been shown in prostate and breast cancers that AR activation might be achieved through ligandindependent mechanisms. These may include increased coactivator expression and activation of several kinases that may directly or indirectly activate AR. [16]. This is the case also in a triple-negative breast cancer, in which AR appears to drive tumor progression. Likewise, other signaling pathways, such as ERK, can enhance AR transcriptional activity through phosphorylation of AR and its co-regulators (for review see [17]). Such mechanisms may be involved in AR activation in GBMs that are usually exposed to minor levels of AR natural ligands (e.g., testosterone and DHT), especially in women. The existence of these mechanisms in brain tumors warrants further investigation.

Since EGFR amplification or activating mutations [1-3] are the most common genetic aberrations associated with malignant glioma, a combination therapy with antiAR agent and EGFR inhibitor might have a beneficial effect in GBM especially in tumors that carry the AR variant and are known to be activated via signal transduction pathways, such as the EGFR pathway [1719]. This hypothesis remains to be investigated in vitro and in vivo.

With the aim of translating the in vitro results to the clinic, an attempt was now made to find in vivo proof of concept. The in vivo experiment described here shows that the AR antagonist enzalutamide efficiently reduces the growth of human glioblastoma. This was recently also demonstrated by Bao et al. [15].

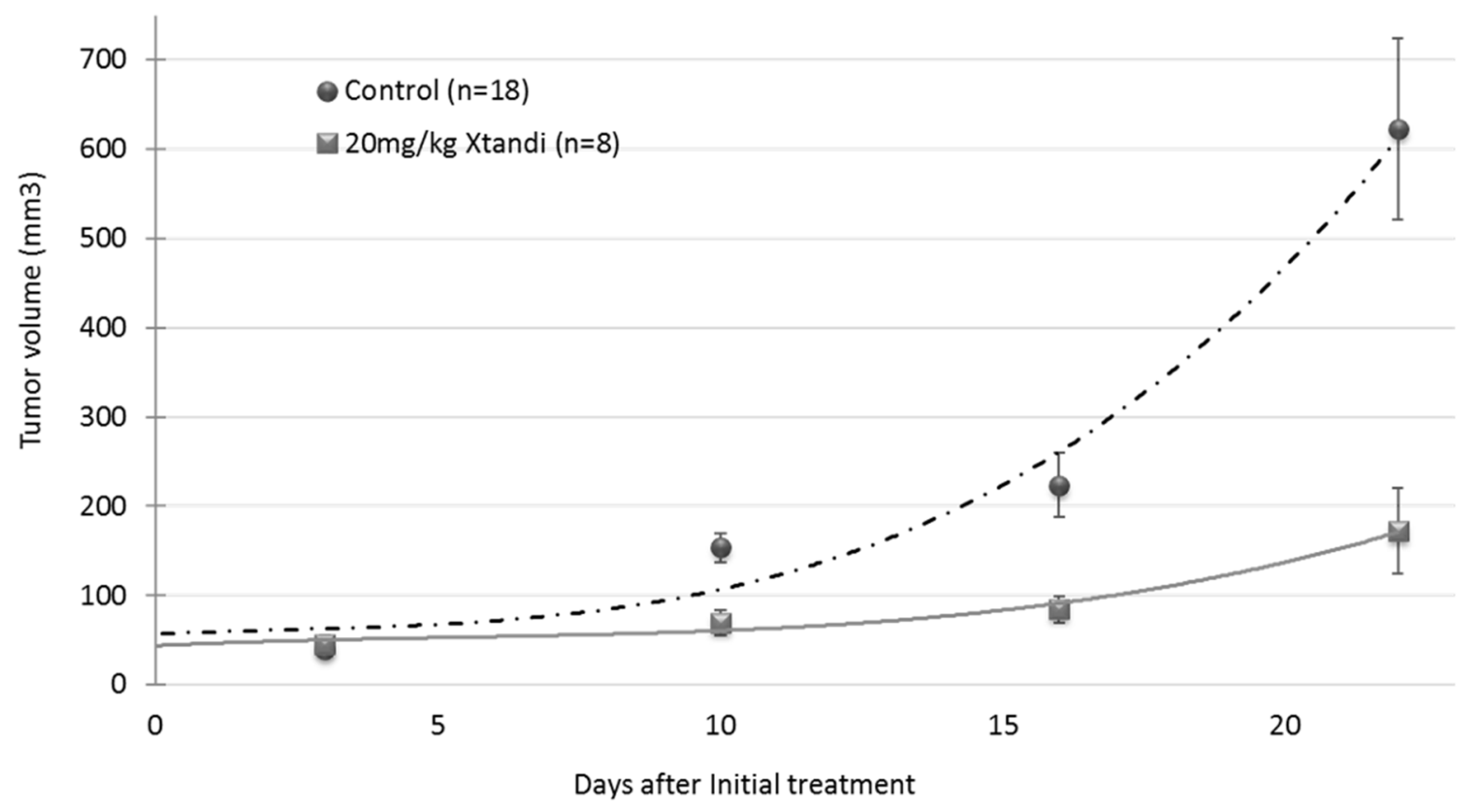

Figure 5: In vivo efficacy of the androgen receptor antagonist enzalutamide (XTANDI) in U87MG human glioblastoma xenografts. A total $5 \times 10^{6}$ tumor cells were inoculated subcutaneously into athymic nude mice, which were randomly assigned to vehicle $(\mathrm{n}=18)$ and XTANDI $(\mathrm{n}=8)$ treated groups. Treatment started on day 7 when the tumors had grown to an approximate 50 -mm3volume. The mice were gavaged orally every second day with $20 / \mathrm{mg} / \mathrm{kg}$ XTANDI or vehicle $(220 \mathrm{mg} / \mathrm{kg}$ caprylocaproyl polyoxylglycerides CH in saline). Each point, representing median tumor volume \pm SEM, is shown with polynomial curve fitting. 
Androgen receptor signaling pathways in gliomas remain largly unknown. A recent study demonstrated that treatment of U87MG with $500 \mathrm{ng} / \mathrm{ml}$ DHT decreased cell apoptosis driven by treatment with $10 \mathrm{ng} / \mathrm{ml}$ TGF $\beta 1$ [21]. The authors concluded that AR signaling might promote tumorigenesis of GBM through TGF $\beta 1$ [21]. Another recent publication proposes AR promotion of glioma progression by suppressing SVIP and p53 [15].

Molecular analysis of tumors is becoming more detailed, allowing therapy tailored to individual tumor types. Thus, it is becoming clear that no single treatment will be the panacea for gliomas. Therefore, if the multifaceted treatment approach is to be successful, it would have to utilize as many targets for therapy as logistically possible. AR is an excellent target for therapy, as it has been shown historically to be an effective target for prostate cancer treatment. In contrast to prostate cancer, efficient penetration of the AR antagonist through the blood-brain-barrier is obligatory for the treatment of brain tumors. Thus, screening of the blood-brain-barrier penetration of an already existing AR antagonist is still warranted in order to test the efficacy of AR antagonist in an intracranial in vivo model. Furthermore, a clear and comprehensive understanding of the mechanism of AR signaling in GBM has yet to be revealed. Following the detection of AR signaling in GBM, the gene expression biomarker of the AR response could be used to assess the responsiveness to AR inhibition in vivo. Hopefully, the results of the present study, in concert with continued laboratory efforts, may lead to a new approach for the treatment of human glioblastoma.

\section{MATERIALS AND METHODS}

\section{Patients and tumors}

A DNA study was performed on 48 paraffinembedded tumors of adult men and women suffering from GBM, (the exact number of samples used for each study is indicated), who were operated at the Hadassah Hebrew University Medical Center. The study was approved by the local institutional research ethics committee, and all patients signed written consent forms (IRB-0099-09HMO).

An expression study was performed on samples from 32 newly diagnosed primary GBM adult men and women patients who were operated at the Tel Aviv Medical Center (Table 2). Patients signed their written informed consent according to an institutional review board-approved protocol (TLV 0307-09).

\section{MGMT promoter methylation, and IDH 1 mutation testing}

MGMT Promoter Methylation, and IDH1-R132H mutation testing were performed as previously described [22-24].

\section{DNA extraction}

DNA was extracted from formalin-fixed, paraffinembedded GBM sample sections with a QIAamp DNA FFPE Tissue Kit (Qiagen, Hildan. Germany), according to the manufacturer's instructions. DNA Samples were quantified with PicoGreen ${ }^{\circledR}$ (Life Technologies, Camarillo, CA, USA).

\section{CNV analysis with droplet digital (dd) PCR}

ddPCR was performed with the QX100 Droplet Digital PCR system (Bio-Rad Laboratories, Hemel Hempstead, UK). The ddPCR reaction mixes in $22 \mu \mathrm{l}$ DDW contained 11ul ddPCR supermix (Bio-Rad), 0.3 $\mu \mathrm{M}$ of each primer and probe and 10 to $30 \mathrm{ng}$ of genomic DNA. Droplet generation and droplet reading for ddPCR were carried out with Bio-Rad reagents. The thermal cycling profile was $95^{\circ} \mathrm{C}: 10^{\prime} 00^{\prime \prime}$ followed by 40 cycles of $\left(95^{\circ} \mathrm{C}: 0^{\prime} 15^{\prime \prime} ; 60^{\circ} \mathrm{C}: 1^{\prime} 00^{\prime \prime}\right)$. Analysis of the ddPCR data was performed with the $\mathrm{Q} \times 100$ analysis software $\mathrm{CNV}$ mode (version 1.2.9.0), and relied on two probes, one specific to the AR labeled with FAM fluorescent signal and an internal reference Ribonuclease P (Rnase P) gene, with a single copy per haplotype that was assayed on the HEX channel. Each experiment was performed twice and in triplicate, with two sets of primers for AR (AR1 and AR2, as indicated below):

AR1-F:AGTGCCTGTTGGAGACAAGA;

AR1-R: ACCACCATGACGCAGAAGAG

AR1-probe (FAM): TCAAACGTATGTCCCTGT CGATCTCA

AR2-F:GGGCACAGAGACCTGGAAA; AR2-R: CCTGACACCCTGATAACTACTCA AR2-Probe (FAM): TCCATGTGCTAACCCATA TCCTGGC

Rnase-P-F:AGATTTGGACCTGCGAGCG; Rnase-P-R:GAGCGGCTGTCTCCACAAGT Rnasep-P-Probe (HEX): TTCTGACCTGAAGG CTCTGCGCG.

\section{RNA extraction, cDNA preparation and qPCR}

Total RNA was isolated from snap frozen gliomas and cell cultures with TRI Reagent ${ }^{\circledR}$ (Sigma-Aldrich, Rehovot, Israel), according to the manufacturer's instructions. Control RNAs were obtained from a commercial mix pooled from 23 donors (mean age, 68 years; 13 men and 10 women) (FirstChoice ${ }^{\circledR}$ Human Brain Reference Total RNA, Thermo Fisher Scientific Inc., Waltham, MA, USA).

cDNA was produced from $0.2 \mathrm{ug}$ total RNA with a qScript cDNA Synthesis Kit (Quanta Biosciences, Gaithersburg, MD, USA), according to the manufacturer's instructions.

Real-time PCR amplification and relative quantification were analyzed with StepOne real time RT 
PCR (Life Technologies). The reaction mix included $1 \mu \mathrm{l}$ cDNA, and $300 \mathrm{nmol} / \mathrm{l}$ of each of the following primers (Syntezza, Jerusalem, Israel):

AR(1)-F:ACCGAGGAGCTTTCCAGAATC, AR(1)-R:AGGCTCTGGGACGCAACCT; AR(2)-F: CTCCTTTGCAGCCTTGCTCTCT, AR(2)-R: ACGTGTAAGTTGCGGAAGCCA HPRT-F:GATGGTCAAGGTCGCAAGC, HPRT-R:ATATCCTACAACAAACTTGTCT GGAA;

TBP-1-F:CCACTCACAGACTCTCACAAC, TBP-1-R:CTGCGGTACAATCCCAGAACT and $5 \mu \mathrm{l}$ of SYBR green mix (Perfecta Syber Green Fast Mix ROX, Quanta Biosciences) in a total $10 \mu \mathrm{l}$ volume. The fold changes of the target mRNAs were normalized to HPRT and TBP1. Then the fold changes of each mRNA were calculated based on the ratio between the analyzed tumor/cell line sample and normal tissue, as indicated. The experiment was repeated three times in triplicate and the results are presented as the mean $\pm \mathrm{SD}$.

\section{mRNA expression of AR splice variants}

AR variant 7 (AR3) was analyzed with quantitative (q)PCR, as described above, with the following primer pair (adopted from Rong Hu et al.) [8]:

\section{AR-7-F:CCATCTTGTCGTCTTCGGAAATGTT}

ATGAAGC

AR-7-R:TTTGAATGAGGCAAGTCAGCCTTTCT.

The resulting $125 \mathrm{bp}$ fragments were also electrophoresed on $3.5 \%$ metaphor, visualized with ethidium bromide and validated according to Sanger sequencing with the forward primer.

\section{Western blot analysis}

Western blotting was performed as previously described [25] with minor modifications. Briefly, tissue samples or cell line pellets were homogenized in 500 ul RIPA Lysis and Extraction Buffer (Thermo Fisher Scientific Inc.) supplemented with protease inhibitors (Thermo Fisher Scientific Inc.). The protein concentration was determined according to the Bradford protein assay (Bio-Rad, Richmond, CA, USA). Tissue/cell line lysates containing $100 \mathrm{ug}$ protein were separated on $4 \%-20 \%$ Tris-Glycine SDS-PAGE gel (Thermo Fisher Scientific Inc) and assessed according to Western blot analysis, and sequential probing with a polyclonal antibody against $\mathrm{AR}$ (N20, 1:200 dilution); a monoclonal anti- GAPDH (0411, diluted 1:10000) (Santa Cruz Biotechnologies, Santa Cruz, CA, USA,) or anti- $\beta$-Actin (AC-74 diluted 1:5000) (Sigma-Aldrich), as indicated, and with the relevant secondary horseradish peroxidase-conjugated antibody (Santa Cruz Biotechnologies).

\section{Cell culture}

Cell lines A172, U87MG and T98G (glioblastoma) were obtained from the American Type Culture Collection (Manassas, VA, USA). A172 and U87MG cells were cultured in Dulbecco's modified Eagle's medium (DMEM) supplemented with $4 \mathrm{mmol} / \mathrm{L}$ L-glutamine, 100 units/ml penicillin, $100 \mu \mathrm{g} / \mathrm{ml}$ streptomycin and with either (as indicated) $10 \%$ of full FBS or charcoal/dextran-treated (stripped) FBS (Biological Industries, Beit Haemek, Israel), to avoid the influence of FBS-derived steroid hormone on AR. The T98G cells were cultured in Eagle's minimum essential medium supplemented with L-glutamine, penicillin and streptomycin and 10\% charcoal/dextrantreated (stripped) FBS. Two glioma-initiating cell (GICs) lines, ZH-161 and ZH-305, were kindly provided by Prof. Michael Weller from the Department of Neurology at the University Hospital Zurich, Switzerland and maintained as described [13, 14]. Briefly, cells were cultured in Neurobasal Medium (Gibco; Thermo Fisher Scientific, Inc., Waltham, MA, USA)) supplemented with B-27 (20 $\mu \mathrm{l} / \mathrm{ml})$ and glutamax $(10 \mu \mathrm{l} / \mathrm{ml})$, fibroblast growth factor (FGF)-2, epidermal growth factor (EGF) $(20 \mathrm{ng} / \mathrm{ml}$ each (Peprotech, Rocky Hill, PA, USA) and heparin (32 IE/ml; Sigma-Aldrich). All cells were maintained in a humidified incubator at $37^{\circ} \mathrm{C}$ in $5 \% \mathrm{CO}^{2}$.

\section{Treatment with AR inhibitors in vitro}

A total $1 \times 10^{3}$ cells were plated in triplicate in 24well plates, (Thermo Fisher Scientific Inc) and allowed to attach overnight. The growth medium was replaced with medium containing physiological amounts (10nM) of DHT (Sigma-Aldrich) [This concentration had no effect on cell viability in any of the cell lines compared with that of cells treated with vehicle $(0.15 \%$ ETOH $)$ (see Figure 2) and the indicated concentrations of AR inhibitors, enzalutamide (A2S technologies, Yavne, Israel) or bicalutamide (Sigma-Aldrich), for $48 \mathrm{~h}$ and/or 72 , as indicated.

\section{siRNA transfection}

A total $2 \times 10^{4}$ A172, U87 and T98G cells were plated in triplicate in $24-w e l l$ plates. After $24 \mathrm{hrs}$ the cells were transfected with $1.2 \mathrm{nM}$ of the indicated siRNA by using INTERFERIN (Polyplus; New York, NY, USA) transfection reagent according to the manufacturer's instructions. AR knockdown was performed with ONTARGETplus Human AR (367) siRNA (Dharmacon; Lafayette, CO, USA). The ON-TARGETplus Nontargeting Pool siRNA (Dharmacon ) served as control. mRNA levels of full length AR were quantified after $24 \mathrm{~h}$ with Real Time RT-PCR by using two sets of primers (AR1 and AR2) as described above and cell survival was measured after $72 \mathrm{~h}$ with the aforementioned method. 


\section{Cell survival analysis}

The crystal violet binding assay was used to measure the viability of A172, U87MG and T98G standard cell lines, as described previously [26]. Briefly, $0.5 \%$ crystal violet (Sigma-Aldrich) was added to each well following fixation of the cells with 4\% paraformaldehyde solution in phosphate-buffered-saline (PBS) (Sigma-Aldrich). The dye was solubilized with $10 \%$ acetic acid (SigmaAldrich) and absorbance was read at $590 \mathrm{~nm}$ in a DTX 880 multimode detector microplate reader (Beckman Coulter, Nyon, Switzerland). The average absorbance value of the control was considered $100 \%$ and the treated sample percentages were calculated according to the average absorbance of the treated samples/the average absorbance of the control.

The viability of the GIC lines was assessed as previously described [27]. Briefly, GICs were seeded in neurobasal medium (Gibco), and incubated for $24 \mathrm{hrs}$. Then exposed to DHT and enzalutamide for $72 \mathrm{hrs}$ at the dosages described above and the 3-(4,5-dimethylthiazol-2yl)-2,5-diphenyltetrazolium bromide (MTT) method was used according to the manufacturer's instructions.

\section{Cell cycle analysis with propidium iodide (PI) DNA staining}

A172, U87 and T98G glioma cell lines were treated with vehicle $(0.15 \%$ ETOH $), 10 \mathrm{~nm}$ of DHT with or without 40 or $80 \mathrm{uM}$ enzalutanide as indicated above for $48 \mathrm{hrs}$ for A172 and U87MG and $72 \mathrm{hrs}$ for T98G. Then the cells were harvested with trypsin and washed with PBS. This was followed by fixation overnight at $-20^{\circ} \mathrm{C}$ in cold $80 \%$ ethanol. After washing the cells with PBS and treatment with $50 \mu \mathrm{l}$ of a $100 \mu \mathrm{g} / \mathrm{ml}$ solution of RNAse, $200 \mu \mathrm{l}$ PI (from a $50 \mu \mathrm{g} / \mathrm{ml}$ stock solution) were added. PI fluorescence intensity was captured with flow cytometry by using the FL2 channel and 488nM laser excitation.

\section{Immunofluorescence staining of cleaved caspase 3}

A172, U87MG and T98G glioma cell lines were treated as indicated above for $72 \mathrm{hrs}$. Then the cells were fixed in $4 \%$ paraformaldehyde for $10 \mathrm{~min}$ at RT and permeabilized with cold methanol for $20 \mathrm{~min}$. The cells were then washed twice with PBS-T and incubated in blocking solution (3\% BSA, $0.1 \%$ Tween in PBS) for $30 \mathrm{~min}$. The cells were incubated with primary antibody (Asp175) (1:50) against Cleaved Caspase-3, (Cell Signaling Technology, Danvers, MA. USA) for $60 \mathrm{~min}$ at $37^{\circ} \mathrm{C}$ and Alexa fluor 488 conjugate secondary antibody (1:200) anti-rabbit IgG (cat No. A21206, Invitrogen, Waltham, Ma., USA) for 60 minutes at RT. The cell nuclei were stained with DAPI (D9542, Sigma-Aldrich) and the cells were visualized and captured with an EVOS ${ }^{\circledR}$ Digital Microscope at $200 \mathrm{x}$ magnification.

\section{In vivo U87MG human glioblastoma xenografts}

Ethical statement: The study was carried out in accordance with the recommendations in the Guide for the Care and Use of Laboratory Animals of the National Institutes of Health. The protocol was approved by the Committee on the Ethics of Animal Experiments of the Hebrew University Medical School (Permit Number: MD16-14864-5). To minimize the suffering of the animals, injections of tumor cells were performed under light anesthesia (ketamine + xylazine, 100 and $5 \mathrm{mg} / \mathrm{kg}$ body weight, respectively). The animals were monitored twice weekly for tumor size and body weight. Upon termination of the experiments, the animals were euthanized by exposure to excess $\mathrm{CO} 2$.

A total $5 \times 10^{6}$ glioblastoma cells (U87MG) were inoculated subcutaneously in the interscapular area of 26 female athymic nude mice. Tumor growth was monitored with the aid of a hand-held Vernier caliper twice weekly. Tumor volume was estimated according to the following equation: width ${ }^{2} \times$ length $/ 2$ (see ref. [28]. On day 7 , when the tumors reached an average volume of about $50 \mathrm{~mm}^{3}$, the mice were randomly assigned to two treatment groups, based on the caliper measurements. All the mice were treated three time weekly by oral gavage with $20 \mathrm{mg} / \mathrm{kg}$ enzalutamide (Astellas Pharma Inc. Tokyo, Japan) $(n=8)$ or vehicle $(220 \mathrm{mg} / \mathrm{kg}$ caprylocaproyl polyoxylglycerides in saline) $(\mathrm{n}=18)$. The enzalutamide dosage for the in vivo experiment was calculated according to the FDA guidelines for scaling of drug doses [dosage-converting tables from humans to mice can be found in [29]], and preclinical trials with enzalutamide in [30]. The mice were sacrificed when their tumors reached a volume of 800 $1000 \mathrm{~mm}^{3}$, as requested by the local animal committee, in order to minimize the animals' suffering.

\section{Statistical analysis}

The statistical significance between the studied groups vs the control groups for each experiment was calculated according to Student's 2-tailed $t$ test.

\section{Author contributions}

All the authors directly participated in the planning, execution, or analysis of the study, and all the authors agree with the content of the manuscript.

\section{ACKNOWLEDGMENTS}

We would like to acknowledge Leslie and Michael Gaffin for their continuous and generous support over the years and for funding this research.

\section{CONFLICTS OF INTEREST}

There are no potential conflicts of interest. 


\section{FUNDING SUPPORT}

This study was supported by the Leslie and Michael Gaffin Foundation for Neuro-Oncology.

\section{REFERENCES}

1. Ekstrand AJ, James CD, Cavenee WK, Seliger B, Pettersson RF, Collins VP. Genes for epidermal growth factor receptor, transforming growth factor alpha, and epidermal growth factor and their expression in human gliomas in vivo. Cancer Res. 1991; 51: 2164-72.

2. Libermann TA, Nusbaum HR, Razon N, Kris R, Lax I, Soreq H, Whittle N, Waterfield MD, Ullrich A, Schlessinger J. Amplification, enhanced expression and possible rearrangement of EGF receptor gene in primary human brain tumours of glial origin. Nature. 1985; 313: 144-7.

3. Nishikawa R, Ji XD, Harmon RC, Lazar CS, Gill GN, Cavenee WK, Huang HJ. A mutant epidermal growth factor receptor common in human glioma confers enhanced tumorigenicity. Proc Natl Acad Sci U S A. 1994; 91: 7727-31.

4. Poisson M, Pertuiset BF, Hauw JJ, Philippon J, Buge A, Moguilewsky M, Philibert D. Steroid hormone receptors in human meningiomas, gliomas and brain metastases. J Neurooncol. 1983; 1: 179-89.

5. Wadosky KM, Koochekpour S. Therapeutic Rationales, Progresses, Failures, and Future Directions for Advanced Prostate Cancer. Int J Biol Sci. 2016; 12: 409-26. https:// doi.org/10.7150/ijbs. 14090 .

6. McNamara KM, Sasano H. Androgen and breast cancer: an update. Curr Opin Endocrinol Diabetes Obes. 2016; 23: 249-56. https://doi.org/10.1097/MED.0000000000000251.

7. Tan MH, Li J, Xu HE, Melcher K, Yong EL. Androgen receptor: structure, role in prostate cancer and drug discovery. Acta Pharmacol Sin. 2015; 36: 3-23. https://doi. org/10.1038/aps.2014.18.

8. Hu R, Dunn TA, Wei S, Isharwal S, Veltri RW, Humphreys E, Han M, Partin AW, Vessella RL, Isaacs WB, Bova GS, Luo J. Ligand-independent androgen receptor variants derived from splicing of cryptic exons signify hormonerefractory prostate cancer. Cancer Res. 2009; 69: 16-22. https://doi.org/10.1158/0008-5472.can-08-2764.

9. Tran C, Ouk S, Clegg NJ, Chen Y, Watson PA, Arora V, Wongvipat J, Smith-Jones PM, Yoo D, Kwon A, Wasielewska T, Welsbie D, Chen CD, et al. Development of a second-generation antiandrogen for treatment of advanced prostate cancer. Science. 2009; 324: 787-90. https://doi. org/10.1126/science.1168175.

10. Lavon I, Zalsman N, Canello T, Charbit H, Zelikovitch B, Mordechai A, Fellig Y, Rabani S, Shahar T, Lossos A. CSIG-13. Androgen receptor is involved in glioblastoma and presents a potential therapeutic target. Neuro-Oncology.
2016; 18: vi43-vi. https://doi.org/10.1093/neuonc/ now212.174

11. Broad Institute TCGA Genome Data Analysis Center. Correlation between mRNA expression and clinical features. Broad Institute of MIT and Harvard; 2016. https:// doi.org/10.7908/C1GH9HBP.

12. van Bokhoven A, Varella-Garcia M, Korch C, Johannes WU, Smith EE, Miller HL, Nordeen SK, Miller GJ, Lucia MS. Molecular characterization of human prostate carcinoma cell lines. Prostate. 2003; 57: 205-25. https://doi. org/10.1002/pros.10290.

13. Papa E, Weller M, Weiss T, Ventura E, Burghardt I, Szabo E. Negative control of the HGF/c-MET pathway by TGF-beta: a new look at the regulation of stemness in glioblastoma. Cell Death Dis. 2017; 8: 3210. https://doi.org/10.1038/ s41419-017-0051-2.

14. Seystahl K, Tritschler I, Szabo E, Tabatabai G, Weller M. Differential regulation of TGF-beta-induced, ALK-5mediated VEGF release by SMAD2/3 versus SMAD1/5/8 signaling in glioblastoma. Neuro Oncol. 2015; 17: 254-65. https://doi.org/10.1093/neuonc/nou218.

15. Bao D, Cheng C, Lan X, Xing R, Chen Z, Zhao H, Sun J, Wang Y, Niu C, Zhang B, Fang S. Regulation of p53(wt) glioma cell proliferation by androgen receptor-mediated inhibition of small $\mathrm{VCP} / \mathrm{p} 97$-interacting protein expression. Oncotarget. 2017; 8: 23142-54. https://doi.org/10.18632/ oncotarget.15509.

16. Cai C, He HH, Chen S, Coleman I, Wang H, Fang Z, Chen S, Nelson PS, Liu XS, Brown M, Balk SP. Androgen receptor gene expression in prostate cancer is directly suppressed by the androgen receptor through recruitment of lysine-specific demethylase 1. Cancer Cell. 2011; 20: 457-71. https://doi.org/10.1016/j.ccr.2011.09.001.

17. Li Y, Chan SC, Brand LJ, Hwang TH, Silverstein KAT, Dehm SM. Androgen Receptor Splice Variants Mediate Enzalutamide Resistance in Castration-Resistant Prostate Cancer Cell Lines. Cancer Research. 2013; 73: 483-9. https://doi.org/10.1158/0008-5472.can-12-3630.

18. Nyquist MD, Li Y, Hwang TH, Manlove LS, Vessella RL, Silverstein KAT, Voytas DF, Dehm SM. TALEN-engineered AR gene rearrangements reveal endocrine uncoupling of androgen receptor in prostate cancer. Proc Natl Acad Sci U S A. 2013; 110: 17492-7. https://doi.org/10.1073/ pnas. 1308587110.

19. Watson PA, Chen YF, Balbas MD, Wongvipat J, Socci ND, Viale A, Kim K, Sawyers CL. Constitutively active androgen receptor splice variants expressed in castrationresistant prostate cancer require full-length androgen receptor. Proc Natl Acad Sci U S A. 2010; 107: 16759-65. https://doi.org/10.1073/pnas.1012443107.

20. Luo J, Attard G, Balk SP, Bevan C, Burnstein K, Cato L, Cherkasov A, De Bono JS, Dong Y, Gao AC, Gleave M, Heemers H, Kanayama M, et al. Role of Androgen Receptor 
Variants in Prostate Cancer: Report from the 2017 Mission Androgen Receptor Variants Meeting. Eur Urol. 2017 Dec 16. https://doi.org/10.1016/j.eururo.2017.11.038. [Epub ahead of print].

21. Yu X, Jiang Y, Wei W, Cong P, Ding Y, Xiang L, Wu K. Androgen receptor signaling regulates growth of glioblastoma multiforme in men. Tumour Biol. 2015; 36: 967-72. https://doi.org/10.1007/s13277-014-2709-z.

22. Lavon I, Refael M, Zelikovitch B, Shalom E, Siegal T. Serum DNA can define tumor-specific genetic and epigenetic markers in gliomas of various grades. Neuro Oncol. 2010; 12: 173-80. https://doi.org/10.1093/neuonc/ nop041.

23. Lavon I, Zrihan D, Zelikovitch B, Fellig Y, Fuchs D, Soffer D, Siegal T. Longitudinal assessment of genetic and epigenetic markers in oligodendrogliomas. Clin Cancer Res. 2007; 13: 1429-37. https://doi.org/10.1158/1078-0432. CCR-06-2050.

24. Shahar T, Granit A, Zrihan D, Canello T, Charbit H, Einstein O, Rozovski U, Elgavish S, Ram Z, Siegal T, Lavon I. Expression level of miRNAs on chromosome 14q32.31 region correlates with tumor aggressiveness and survival of glioblastoma patients. J Neurooncol. 2016; 130: 413-22. https://doi.org/10.1007/s11060-016-2248-0.
25. Lavon I, Goldberg I, Amit S, Landsman L, Jung S, Tsuberi BZ, Barshack I, Kopolovic J, Galun E, Bujard H, BenNeriah Y. High susceptibility to bacterial infection, but no liver dysfunction, in mice compromised for hepatocyte NF-kappaB activation. Nat Med. 2000; 6: 573-7. https://doi. org/10.1038/75057.

26. Canello T, Ovadia H, Refael M, Zrihan D, Siegal T, Lavon I. Antineoplastic effect of decoy oligonucleotide derived from MGMT enhancer. PLoS One. 2014; 9: e113854. https://doi.org/10.1371/journal.pone.0113854.

27. Schneider H, Weller M. Boswellic acid activity against glioblastoma stem-like cells. Oncol Lett. 2016; 11: 418792. https://doi.org/10.3892/ol.2016.4516.

28. Euhus DM, Hudd C, LaRegina MC, Johnson FE. Tumor measurement in the nude mouse. J Surg Oncol. 1986; 31 : 229-34

29. Nair AB, Jacob S. A simple practice guide for dose conversion between animals and human. Journal of Basic and Clinical Pharmacy. 2016; 7: 27-31. https://doi. org/10.4103/0976-0105.177703.

30. Guerrero J, Alfaro IE, Gomez F, Protter AA, Bernales S. Enzalutamide, an androgen receptor signaling inhibitor, induces tumor regression in a mouse model of castrationresistant prostate cancer. Prostate. 2013; 73: 1291-305. https://doi.org/10.1002/pros.22674. 